\title{
Atravessamento das ações do professor no espaço e no tempo
}

\author{
Actions crossing of the teachers in the space and in the time \\ Cruzamiento de las acciones del maestro en el espacio y en el tiempo
}

\section{Resumo}

Esta pesquisa, como parte de uma tese de doutorado, tem como objetivo apresentar as reflexões acerca dos diferentes relatos de professores em relação à outros professores que marcaram suas escolhas profissionais, desde os anos iniciais até a graduação. Desta forma, compreender a gênese e o desenvolvimento da profissão docente faz-se necessário para investigar e analisar o atravessamento das ações do professor no espaço e no tempo. Para isso, foi realizada entrevista semi-estruturada com professores de Ciências e/ou Biologia que lecionaram nas décadas de 1970, 1980, 1990, 2000, 2010, sendo dois professores de cada período sinalizado, totalizando 10 professores entrevistados, pertencentes ao Núcleo Regional de Educação (NRE) do município de Goioerê-PR. Com base na metodologia da Análise Textual Discursiva (ATD) proposta por Moraes e Galiazzi (2011), foi possível compreender a influência dos professores de Ciências e Biologia na escolha da profissão dos entrevistados. Também as práticas docentes dos professores marcantes, os quais deixaram registros positivos e/ou negativos nas lembranças de seus alunos, práticas que atravessam o tempo e o espaço, perpetuando sua presença e ações.

Palavras-chave: Ciências; Professor; Profissão docente; Professores marcantes.

\begin{abstract}
The goal of this study is to show the reflections of different teachers' reports in relation to other teachers that were significant in their career choices from beginning years of study to graduation level. Thus, understanding the genesis and the development of the teaching are necessary to learn and to analyze the teacher's actions in that time. For that, was carried out a half-structured interview with Science and/or Biology Teachers that taught in the years 1970, 1980, 1990, 2000 and 2010. Two teachers from each indicated period were interviewed. All the 10 teachers that answered the interview are from the Regional Education Center (REC) from Goioere-PR. Following the methodology of the Textual Discursive Analysis proposed by Moraes and Galiazzi (2011), it was possible to understand the influences of the Science and Biology teachers in their professional choices. Also, the teaching practices of the outstanding teachers who left positive and/or negative memories in their students were considered, practices that crossing the time and the space, perpetuating your presence and actions.
\end{abstract}

Keywords: Science; Teacher; Teaching profession; Outstanding teachers.

\section{Resumen}

Esta pesquisa, como parte de una tesis de doctorado, tiene como objetivo presentar las reflexiones acerca de los diferentes relatos de maestros en relación a otros maestros que definieron sus elecciones profesionales, desde los años iniciales hasta la graduación. De esta manera, comprender la génesis y la desenvoltura de la profesión docente es necesario para investigar y analizar el cruzamiento de las acciones del maestro en el espacio y en el tiempo. Por eso fue realizada una entrevista medio estructurada con maestros de Ciencias y/o Biología que enseñaron en las décadas de 1970, 1980, 1990, 2000, 2010, siendo dos maestros de cada periodo señalados, totalizando 10 maestros entrevistados, pertenecientes al Núcleo Regional de Educación (NRE) del municipio de Goioerê-PR. Con base en la metodología de Análisis Textual Discursiva (ATD) propuesta por Moraes y Galiazzi (2011), fue posible comprender la influencia de los maestros de Ciencias y Biología en la elección de la profesión de los entrevistados. También las prácticas docentes de los maestros sobresalientes, los cuales dejaron registros positivos y/o negativos en los recuerdos de sus alumnos, prácticas que cruzaron el tiempo y el espacio perpetuando su presencia y acciones.

Palabras clave: Ciencias; Maestro/a; Profesión docente; Maestros sobresalientes. 


\section{Introdução}

Quem é o professor? Este questionamento aponta para diversas reflexões acerca da profissão docente, a saber: as influências e experiências da vida de estudante durante a infância até a conclusão do Ensino Médio, a escolha do indivíduo para cursar uma licenciatura, a formação inicial para professores, os currículos de formação, as crenças, a cultura, e todos os aspectos que envolvem a constituição do homem, em seu processo de humanização. Uma questão tão simples, mas ao mesmo tempo complexa considerando as diversas compreensões manifestadas nas práticas docentes.

A opção pela docência como profissão perpassa vários fatores de caráter emocional, cultural, psicológico, pois são motivações internas e externas de experiências e vivências, seja na escola ou em casa. Tais fatores além de influenciarem na opção pela profissão refletem, também, na prática docente. Nesse sentido, Nóvoa (1992), argumenta que cada docente constrói dentro de si seu jeito de ser professor. Contudo, ao estudarmos a profissão docente é necessário compreendê-la nas suas diferentes dimensões.

Assim, fica evidente que a formação de professores na contemporaneidade, precisa refletir sobre a ausência da prática e a falta de articulação desta com a teoria, além também do distanciamento da rede básica de ensino e o ensino superior, ou seja, o distanciamento entre a realidade de trabalho, e o local de formação destes profissionais.

Desta forma, compreendemos que o professor tem um de seus alicerces no desenvolvimento de sua prática, no cotidiano em sala de aula, na interação com os alunos e com o conteúdo a ser ensinado. Além da articulação que o docente estabelece entre os conteúdos específicos da disciplina e os conteúdos pedagógicos, já que a DCN 02/2015 estabelece a estrutura dos currículos de formação inicial com conteúdos específicos da área de conhecimento, seus fundamentos e metodologias, como também os conteúdos relacionados aos fundamentos da educação, por exemplo, políticas públicas, gestão da educação, diversidades étnico-racial, Língua Brasileira de Sinais (Libras).

Destacamos o efeito espelho como explicam Quadros et al. (2005), ao discutirem sobre a prática do professor, a influência das memórias das experiências vividas em sala de aula como alunos, as quais muitas vezes se repetem na atuação como professores, podendo ser experiências obtidas tanto na escolarização básica como no ensino superior, por isso a atuação do docente no curso de licenciatura tem grande interferência no tipo de professores que estão formando.

Neste sentido, é inegável que as experiências que os professores vivenciaram em sala de aula marcaram profundamente a construção de suas identidades profissional. Deste modo, este artigo, como parte de uma tese de doutorado, tem como objetivo apresentar as reflexões acerca dos diferentes relatos de professores sobre os professores que marcaram as suas escolhas e práticas docentes, desde os anos iniciais até a graduação.

\subsection{Percurso histórico da profissão docente}

Compreender a gênese e o desenvolvimento da profissão docente faz-se necessário para investigar e analisar o atravessamento das ações do professor no espaço e no tempo. Neste sentido, recorremos a Grécia Antiga, o berço da civilização ocidental para iniciar a trajetória da profissão docente, percorrendo o período romano, a idade média, a idade moderna até o contexto atual, na contemporaneidade.

Platão em sua obra "A República", refere-se a Homero como o educador de toda a Grécia, sendo o mais antigo documento que faz referência à educação arcaica. Homero, escolhido e conservado como texto base na educação, era representante exímio do ideal grego, a ética cavalheiresca, a formação do homem belo e bom, pois a associação da estética e da ética é a característica primitiva do pensamento grego-primitivo (Jaeger, 2001). 
A poesia de Homero foi um dos principais instrumentos educadores da Grécia Antiga, os poetas serviam para o aluno encontrar modelos do que se espera dele no mundo, por exemplo, seja determinado como Ulisses ${ }^{1}$, ou, não fuja, como Páris ${ }^{2}$ da luta. A educação buscava a formação do homem integral, com a aquisição de virtudes, o professor, neste período chamado de mestre, era persistente e atento aos seus alunos ao ministrar o conhecimento.

Entre os mestres que contribuem para a formação da criança, está o pedagogo, o qual era um escravo ou servidor encarregado de levar as crianças à escola e, tinham autoridade sobre eles, visto que estavam sob seus cuidados. Sua função ultrapassa simplesmente a proteção da criança dos perigos no trajeto, mas as ensinavam boas maneiras, formava seu caráter e sua moralidade. Os mestres incubem aos pedagogos a tarefa de repetidor, ou seja, ensinar as lições (Marrou, 2017).

Destaca-se o período clássico da Grécia Antiga que representa seu apogeu pela herança cultural que deixou para o mundo ocidental, pela fascinante produção nas artes, literatura e filosofia com os clássicos filósofos Sócrates, Platão e Aristóteles. Sócrates idealizou um método denominado Pedagogia do Diálogo, composto por duas partes, a saber: a ironia, ignorando o conhecimento e a maiêutica, e a arte de parir novas ideias (Aranha, 2006).

No período Romano, a educação está associada aos princípios humanos da valorização das ações do homem, sua reflexão e contemplação; aos princípios políticos, sociais, e culturais como as normas jurídicas. Os romanos tinham por meio da educação uma mentalidade prática em busca de resultados concretos. Destaca-se Quintiliano, considerado o maior pedagogo romano, valorizava o valor humanístico e espiritual da educação, e, o estudo psicológico do aluno (Luzuriaga, 1983).

Na idade Média, a educação é marcada pela patrística, sendo os educadores os padres da igreja católica, e pela escolástica, a qual conciliava a razão filosófica grega com a fé cristã. Dias (2012) faz uma análise com base nos escritos de dois autores medievais que apresentam o lúdico no ensino por meio de uma peça de teatro e um jogo de perguntas e respostas, as quais evidenciam preocupações com a formação filosófica e com a essência do homem, a autora destaca o papel desempenhado pelo professor neste contexto:

[...] O mestre ensina o discípulo a pensar, a refletir. A partir disso o encaminha para a compreensão do significado da existência, assim como para o entendimento de que a vida deve ser sustentada pelo exercício das virtudes, já que o que a caracteriza é a transitoriedade, aquilo que nos escapa sem que o percebamos [...] (Dias, 2012, p.53-54).

O professor, chamado de mestre, se preocupava com o ensino dos conteúdos medievais que se baseavam no Trivium (gramática, dialética e retórica) e o Quadrivium (aritmética, geometria, astronomia e música) e estes sempre associados ao ensino e exercício de uma virtude. A escolástica exercia forte influência sobre a pedagogia católica e, consequentemente, na Companhia de Jesus, que introduziu o ensino escolástico no Brasil.

Com a chegada dos padres jesuítas em 1549 no Brasil, tem início o processo educativo em nosso país. Durante quase dois séculos, XVI e XVII, eles foram os educadores, possibilitaram o ensino e a aprendizagem baseados em seu manual de estudos chamado "Ratio Studiorum", o qual oferecia aos sacerdotes professores os planejamentos, programas e metodologias pautadas na razão mediada pela fé (Aranha, 2006).

Em 1759, a Companhia de Jesus é expulsa do Brasil por Marques de Pombal devido a insatisfação com o trabalho educacional catequético que estava sendo desenvolvido no país, o qual possibilitava aos jesuítas uma certa forma de poder econômico e cultural hegemônico. Assim, deu-se início a um processo de laicização no ensino com o envio dos professores régios e, também, a "[...] uma organização e normatização do exercício da profissão docente, porém somente após a Lei Geral do Ensino de 1827 que a intervenção estatal se efetivará quanto à organização dos professores” (Castro, 2006, p.5).

\footnotetext{
${ }^{1}$ Ulisses, protagonista da obra "Odisseia" de Homero a qual relata o retorno de Ulisses (Odisseus, em grego) à ilha de Ítaca após a Guerra de Tróia (Aranha, 2006).

${ }^{2}$ Páris, personagem da obra "Ilíada" de Homero que retrata a Guerra de Tróia (Aranha, 2006).
} 
Nóvoa (1995) explica que a gênese da profissão professor se encontra em meio às congregações religiosas, que se tornou em verdadeiras congregações docentes "[...] ao longo dos séculos XVII e XVIII, os jesuítas e os oratorianos, por exemplo, foram progressivamente configurando um corpo de saberes e de técnicas e um conjunto de normas e de valores específicos da profissão docente.” (p.15). O autor expõe que é neste período que a imagem da profissão docente como sacerdócio é consolidada, pois são apresentados um universo simbólico envolto da mística da sua atuação ser um dom, uma missão. Destaca-se que alguns elementos aparecem nos discursos dos professores até hoje como fé, missão, crença, que estão associadas ao período histórico em que a prática pedagógica passa a ser vista como sacerdócio.

A preocupação com a formação de professores aparece no cenário brasileiro antes mesmo da independência do Brasil, Rui Barbosa tece uma crítica a circunstância em que se encontrava o ensino superior brasileiro, especialmente no Direito e explicitava a carência de uma reforma completa dos métodos e dos mestres. Porém, somente após a independência do Brasil que explicitamente se inicia a discussão acerca da organização da instrução popular (Borges, Aquino \& Puentes, 2011).

As primeiras escolas normais brasileiras foram estabelecidas por meio das Províncias com a reforma constitucional de 1834, sendo a primeira na Província do Rio de Janeiro, na cidade de Niterói, em 1935. A "Escola Normal” teve como objetivo formar professores para o ensino primário, que ainda não possuíam a formação necessária, contudo, sem êxito, já que faltava professores com formação adequada para atuarem e formarem outros professores e, para atender a demanda, pessoas nãohabilitadas começaram a atuar (Tanuri, 2000).

Borges, Aquino e Puentes (2011) explicam que no início as Escolas Normais favoreciam uma formação específica, sendo guiada por direcionamentos pedagógico-didáticos, porém, não era o que acontecia no desenvolvimento destas formações, sendo maior a preocupação com o domínio dos conteúdos que eram ensinados nas escolas de primeiras letras a ponto de desconsiderar a preparação didático-pedagógica.

Desta forma, podemos analisar que desde o início da sua formação sistematizada no Brasil o professor passa pelo engrandecimento dos conteúdos científicos em detrimento dos conteúdos didático-pedagógicos. Este critério reflete ainda nos dias atuais quanto as identidades profissionais docentes, ou seja, uma visão estereotipada de que para ser professor é necessário apenas saber o conteúdo a ser ensinado.

Em 1932, quando publicado o Manifesto dos Pioneiros assinado por Fernando de Azevedo e 26 educadores brasileiros, dentre as várias reivindicações, fica evidente a solicitação de autonomia para os educadores e uma organização educacional, pois apesar das "Escolas Normais" se desenvolverem no período republicano elas não tinham uma organização fundada em diretrizes pelo Governo Federal (Castro, 2006). Portanto, as discussões acerca da educação adquirem uma maior proporção devido a divulgação dos fundamentos do escolanovismo que proporcionam reformas estaduais do ensino primário e normal na tentativa de superar a escola tradicional rígida, magistrocêntrica e voltada para a memorização de conteúdos. Defendiam métodos ativos de educação, tendo em vista também a formação global do aluno.

Neste sentido, os escolanovistas concebem o professor como um mediador, responsável por acompanhar o trabalho dos alunos e animar as atividades escolares, pois o processo educacional está pautado no aluno que aprende fazendo. "O esforço e a disciplina são produtos do interesse, por isso é importante para o educador a descoberta dos reais interesses da criança [...] Apenas assim a experiência adquire valor educativo.” (Aranha, 2006, p. 262).

Nesse contexto, a formação era constituída de disciplinas específicas nos três primeiros anos de formação e depois um ano de disciplinas pedagógicas, conhecido como modelo "3+1" (Pereira, 1999). Esse modelo de formação docente, conhecido também como modelo de racionalidade técnica ou educação tecnicista, visou formar o professor como um técnico que reproduz com rigor as técnicas do conhecimento científico e pedagógico em sua prática. Desta forma, é possível observar que, mesmo com os fundamentos da Escola Nova, as reformas os argumentos para superar a escola tradicional, emerge a formação pautada na racionalidade técnica, que de certa forma ainda não foi totalmente superada. 
Neste sentido, a teoria curricular pós-crítica que fundamenta os currículos brasileiros vem ao encontro destas necessidades apresentadas por esta sociedade pós-moderna, a qual estabelece a relevância de trabalhar eixos temáticos como etnia, gênero, diversidade, multiculturalismo, sustentabilidade, cidadania associados aos conteúdos disciplinares. Espera-se de um professor hoje que ele seja um mediador do processo de ensino e aprendizagem, e, que esteja atento a formação do ser integral, não somente do intelecto.

A partir deste breve histórico, é possível tecer algumas reflexões acerca da profissão docente, as quais estão associadas as condições sociais, políticas e culturais de cada momento. Assim, percebemos as mudanças que vão acontecendo no decorrer da história acerca do papel do professor, suas atribuições, sua valorização, o conhecimento que lhe é exigido em diferentes momentos.

\section{Metodologia}

O presente estudo se configura como uma pesquisa qualitativa que segundo Flick (2009) envolve diferentes variáveis, entre elas a comunicação do pesquisador em campo, sua subjetividade e observações que se explicita na interpretação e análise crítica dos dados. "A pesquisa qualitativa é de particular relevância ao estudo das relações sociais devido à pluralização das esferas da vida" (p.20).

Essa investigação ocorreu por meio de entrevista semi-estruturada realizada com professores de Ciências e/ou Biologia que lecionaram nas décadas de 1970, 1980, 1990, 2000, 2010, sendo dois professores de cada período sinalizado, totalizando 10 professores entrevistados (identificados com códigos de P1 a P10). A escolha destes professores ocorreu por meio do Núcleo Regional de Educação (NRE) do município de Goioerê-PR, que inclui os municípios de: Boa Esperança, Goioerê, Janiópolis, Juranda, Mariluz, Moreira Sales, Quarto Centenário, Rancho Alegre do Oeste e Ubiratã.

O encontro com os entrevistados ocorreu por duas etapas: a) O primeiro contato foi realizado com o NRE de Goioerê, e, diretamente com os diretores de algumas escolas próximas da pesquisadora a fim de indicações de professores de Ciências e Biologia que lecionaram nas décadas de 1970 a 2010. b) Após identificados estes professores foram informados sobre a natureza do projeto de pesquisa, salientado a importância da sua colaboração e convidados a participarem voluntariamente mediante a assinatura de Termo de Consentimento Livre e Esclarecido - TCLE, aprovado pelo Comitê de Ética CAAE: 26300719.0.0000.0104, concordando em participar desta pesquisa, bem como autorizaram a utilização das gravações de áudio das entrevistas.

A análise dos dados foi realizada com base na metodologia da Análise Textual Discursiva (ATD) proposta por Moraes e Galiazzi (2011), a qual assume pressupostos que a localizam entre os extremos da Análise de Conteúdo e Análise do Discurso. Para os autores é um processo auto-organizado de construção de novas compreensões e significados acerca de um fenômeno investigado que emergem de uma sequência, a qual compõem um ciclo: 1. Desmontagem dos textos: o processo de unitarização; com leitura; significação e separação de fragmentos de todo o corpus da pesquisa, que é formado pelas transcrições das entrevistas realizadas com os 10 professores para a construção das unidades de análise; 2. Estabelecendo relações: o processo de categorização, que nesta pesquisa se deu por meio do método intuitivo, o qual "[...] pretende superar a racionalidade linear que está implícita tanto no método dedutivo quanto no indutivo e defende que as categorias tenham sentido a partir do fenômeno focalizado como um todo." (Moraes \& Galiazzi, 2011, p. 24). Este artigo apresenta parte de uma tese de doutorado, portanto será apresentada a discussão e o metatexto de uma categoria; 3. Captando o novo emergente: expressando as compreensões atingidas. Com base na impregnação do corpus da pesquisa, possibilitado pelas etapas anteriores, da categorização produzida pelo método intuitivo, emerge as novas compreensões e sua comunicação por meio dos metatextos que é a última etapa deste ciclo de análise. Nesta pesquisa, construímos um metatexto para a categoria - 
Atravessamento das ações do professor no espaço e no tempo - o qual apresentam sua estrutura descritiva, interpretativa e argumentativa.

\section{Atravessamento das Ações do Professor no Tempo e no Espaço}

As discussões nesta categoria apresentam as reflexões acerca dos diferentes relatos de professores que marcaram a vida dos entrevistados, ou seja, rememorizações que influenciaram em suas escolhas e práticas oriundas desde os anos iniciais até a graduação. Algumas unidades de significado apontaram para a escolha da profissão docente que se desenvolveu a partir do encantamento com as Ciências, por meio da influência de pais professores, do contexto em que viviam, como também a influência de professores de Ciências e Biologia que marcaram a vida dos entrevistados. Também as práticas docentes dos professores marcantes, docentes que deixaram registros positivos e/ou negativos nas lembranças de seus alunos, práticas que atravessam o tempo e o espaço, perpetuando sua presença e ações, conforme destacamos nesta fala de P4 "Inclusive, a minha professora da terceira série, do terceiro ano, eu me lembro dela até hoje, nunca esqueci".

A educação passa por um momento de dilemas e desafios, inseguranças e incertezas conforme apontam Wagner \& Carlesso (2019), neste sentido, consideramos relevante refletir sobre a escolha da docência como profissão, e, podemos perceber a importância da prática do professor, a qual pode ser uma alavanca motivadora para a continuidade nos estudos e identificação com a profissão docente, inclusive na escolha da licenciatura que normalmente é justificada pela prática de outros professores.

"[...] e foi por ela mesmo que eu cursei ciências sabe, porque ela era minha professora de ciências e matemática no ensino fundamental." (P1)

"Então a professora de Biologia foi uma delas, porque ela é apaixonada por biologia, sempre foi. E eu acho que ela passava um pouco dessa paixão para a gente, então quando estava no ensino médio, embora eu não tivesse certeza do que eu queria, eu sabia que era alguma coisa na área biológica. Então acho que ela foi uma grande influenciadora." (P8)

Apesar de autores como Salla e Ratier (2010) e Wagner e Carlesso (2019) descrevem que a desvalorização profissional do professor é uma das razões para o alto índice de desistência e da baixa atratividade na carreira docente, a presença do professor e sua entrega à disciplina e conteúdo que ministram são marcas registradas nas memórias de muitas pessoas. Os excertos apresentados anteriormente sinalizam essas lembranças de professores que fizeram parte da trajetória estudantil dos professores entrevistados.

Penna (2014) desenvolveu uma pesquisa com professores de história e sua escolha pela profissão, partindo da hipótese de que alunos da educação básica que tiveram professores marcantes de história acabam optando pelo curso de história ao ingressarem na universidade por influência deste professor. Esta hipótese foi confirmada em sua pesquisa, a maioria dos entrevistados revelou que um professor havia sido o principal fator como influência para o curso de história. A confirmação dessa questão não é diferente para esta pesquisa com professores de Ciências e Biologia, pois a maioria dos professores entrevistados relataram situações em sala de aula com os professores de Ciências que tiveram durante a Educação Básica e que marcaram profundamente o interesse por esta área de ensino.

Uma personalidade influente deixa registros na vida das pessoas. O professor é um profissional que naturalmente exerce influência em seus alunos, porém, sabemos que uns marcam mais que outros e, quais são as características deste professor marcante, quais foram as ações que atravessam o tempo e influenciam até na escolha da profissão dos jovens? No desenvolvimento desta pesquisa essas características vão ficando explicitas pelos relatos dos entrevistados. Neste sentido, Castanho (2001) nos convida a sermos professores marcantes e inesquecíveis na vida dos alunos, já que a palavra tem poder, e 
este poder deve ser usado pelo professor para promover o aluno, ajudar a torná-lo melhor em suas potencialidades, e se encontrar em sua trajetória profissional.

"[...] como eu trabalhei no museu de ciências e o público era a mulecada então eu fui pegando o jeito. Minha professora de didática gostou das aulas, ela falou "Não, professor, o senhor é um professor bom”, ela me chamou no projeto na época [...] dai ela me chamou atenção "Você vai se dar bem na profissão". "(P9)

Os bons professores são considerados aqueles que estimulam a independência dos alunos e os professores que marcam seus alunos geralmente são aqueles que suas palavras repercutem positivamente neles. Castanho (2001) reforça de que cada palavra dita é carregada de significações que repercutem de forma diferente na estrutura cognitiva de cada aluno, dependendo de sua história pessoal. O entrevistado P9 nos conta que durante a graduação de Ciências Biológicas seu objetivo estava mais voltado a pesquisa e não tinha interesse pela docência, porém devido ao projeto que teve oportunidade de participar no museu de Ciências da Universidade, foi desenvolvendo o gosto pela profissão, o que foi confirmado e incentivado por sua professora de didática. Ele reforça ao relatar no excerto apresentado que a fala de sua professora foi determinante para ele escolher ser professor.

Mas, não são somente as palavras que marcam, um professor precisa ser um exemplo também na sua postura em sala de aula. A forma como desenvolve sua prática pedagógica é capaz de surpreender e deixar cenas registradas nas lembranças de seus alunos. Castanho (2001) descreve que um professor marcante não dá apenas aulas expositivas, embora elas precisem ser as melhores, mas utiliza de várias técnicas em sala de aula, promove várias atividades diferentes e propicia interação grupal. Podemos observar nos excertos a seguir, extraídos dos relatos de alguns entrevistados, o quanto as aulas que saiam da técnica expositiva deixaram marcas em sua memória.

"[...] Menina, você acredita que ela sacrificou um cachorro e fez uma aula de ciências, abrindo o cachorro para nós." (P5)

"Mas eu sempre gostei muito das aulas que a minha professora dava, [...] ela trazia muitas figuras coloridas em livros, porque era o único recurso que tinha, nós confeccionávamos cartazes, então era uma aula diferente." (P7)

“[...] ela deu ciências para mim, ela era muito rígida, mas ela me marcou muito porque as feiras de ciências dela, quem fazia projeto com ela, eram impecáveis. Então eu recordo de vários trabalhos que a gente fez em ciências, por causa dela." (P8)

Para Tardif (2002) e Paredes e Guimarães (2012) a utilização de novas metodologias e abordagens de ensino facilitam o processo de ensino e aprendizagem, bem como as compreensões do professor de como os alunos constroem seus conhecimentos. Assim, saber dirigir a atividade dos alunos implica em o professor ser o orientador dos grupos de "pesquisadores iniciantes". Não se obtém um ensino e aprendizagem efetivos com um professor que impõe uma atividade ao aluno, tornando para ele uma obrigação. Para tanto, é importante favorecer um bom clima no funcionamento da aula, uma relação professor e aluno cordial, onde o docente demonstre seu interesse pelo desenvolvimento da tarefa de cada aluno, assim trabalhar de forma ordenada as atividades contribuem para resultados frutíferos no agir do professor.

Mediante as vantagens e restrições de uma metodologia, Laburú, Arruda e Nardi (2003) explanam sobre o pluralismo metodológico no ensino de ciências, em que o professor não precisa se prender a uma metodologia e sim conhece-las para poder utiliza-las em suas diferentes aulas adequando a realidade de cada turma. 
Neste sentido, considerando a relevância da formação ambiental ${ }^{3}$ no percurso da formação inicial dos novos professores. Alarcão (2011) afirma que os professores têm responsabilidade na ajuda ao desenvolvimento desta capacidade de pensar autônoma e sistematicamente do acadêmico e esta ajuda está concentrada principalmente em sua prática pedagógica, sua postura e atuação em sala de aula. Por isso, Luiz (2017, p. 40) afirma que a prática reflexiva, e, a capacidade de pensar autônoma do professor possibilita romper com o ciclo "eu aprendo assim, eu faço assim".

Ademais, o modo como os sujeitos se relacionavam com os seus professores durante o longo período como aluno, desde a alfabetização até a graduação permite a construção de ideias, comportamentos e atitudes sobre o ensino, que são elementos significativos na constituição de Identidade(s) docente. Silva $(2009$, p. 50) afirma que "[...] a perspectiva dominante sobre a formação da identidade profissional centraliza-se na discussão em torno das experiências de escolarização que foram vividas por eles."

Carvalho e Gil-Perez (2001, p.27) denominam as experiências dos professores durante a escolarização como formação ambiental e, para os autores, a interferência desta formação ambiental é ampla "porque responde a experiências reiteradas e se adquire de forma não-reflexiva como algo natural, óbvio, o chamado "senso comum", escapando assim à crítica e transformando-se em um verdadeiro obstáculo".

Portanto, podemos afirmar que, estes costumes e ideias vivenciados em sala de aula como aluno, não são apenas lembranças das experiências escolares, mas são elementos determinantes que atuam na formação da identidade dos futuros professores. Tardif (2008), explica que a docência é uma profissão que possibilita o contato desde a infância e por um longo período, desse modo, as experiências escolares marcam a história dos sujeitos e consequentemente influenciam em suas escolhas e práticas.

Quanto a relevância do domínio do conhecimento científico a ser ensinado, os professores entrevistados demonstraram em suas falas a preocupação em estudar e dominar o assunto a ser trabalhado em sala de aula, principalmente quando estavam nos primeiros anos de profissão. Estes professores percebem que esta necessidade formativa é a base para um bom professor, a partir dela que as metodologias de ensino podem ser construídas e desenvolvidas no processo de ensino e aprendizagem. Além de apresentarem lembranças de professores que admiravam pelo domínio de conteúdo no período em que eram alunos tanto da rede básica quanto na graduação.

"[...] a professora de geografia, [...] a única professora que ela chegava só com o apagador e livro de chamada [...] os alunos admiravam ela, porque ela não lia nada, ela chegava e dava aquela aula sem nada, e todo mundo falava "Ela não olha o livro, ela não usa livro" (P9)

"Esta minha professora da faculdade, que foi minha orientadora do mestrado, eu tive aula com ela no primeiro ano da faculdade de fisiologia, e quando eu vi a aula dela eu fiquei impressionada, eu gostei da disciplina mais pela forma que ela explicava, ela pegava o giz e ela não copiava nada, ela escrevia tudo de cabeça o quadro inteiro, começava explicar de uma forma tão segura e com tanto conhecimento, domínio daquele conteúdo, que as pessoas ficavam admiradas, e todos os alunos prestavam atenção, e se interessavam por aquele assunto, independente se gostava ou não do assunto." (P10)

"[...] o professor era um padre, também do rito ucraniano, os padres eles eram extremamente preparados, porque além de eles fazerem a teologia no Brasil eles faziam uma especialização em Roma, de três, quatro, cinco anos. E esse padre, ele lecionava latim e ele era extremamente rigoroso." (P2)

Diante da indagação sobre o "saber" e "saber fazer" para que os professores de ciências atuem com qualidade no campo do ensino, Carvalho e Gil-Pérez (1995) expõem as necessidades formativas para os professores de ciências. Estas foram elaboradas a partir da análise crítica da formação de professores no Brasil e das contribuições de grupos de professores que

${ }^{3} \mathrm{O}$ longo período como aluno, permite a construção de ideias, comportamentos e atitudes sobre o ensino; os autores Carvalho e Gil-Perez (2001) chamam esse percurso de formação "ambiental". 
abordaram coletivamente a questão, e proporciona reflexão, debate e aprofundamento. Tais grupos possibilitam romper com as visões simplistas que cada professor isolado ou no coletivo costuma expor.

Segundo esses autores, as necessidades formativas apontadas podem orientar o trabalho de formação de professores, são elas: conhecer a matéria a ser ensinada; conhecer e questionar o pensamento docente espontâneo; adquirir conhecimentos teóricos sobre a aprendizagem e aprendizagem de ciências; crítica fundamentada no ensino habitual; saber preparar atividades; saber dirigir a atividade dos alunos; saber avaliar; adquirir a formação necessária para associar ensino e pesquisa didática. $\mathrm{Na}$ sequência fazemos uma breve síntese, de acordo com o proposto por Carvalho e Gil-Pérez (1995), das necessidades formativas para o professor de ciências.

Conhecer a matéria a ser ensinada, pode parecer supérfluo, porém, pesquisas apontam a carência do conhecimento científico de muitos professores o que interfere diretamente no envolvimento do mesmo em atividades inovadoras e criativas, assim o professor é apenas o transmissor dos conteúdos do livro. Acentua-se que é preciso o professor conhecer a história das ciências, as orientações metodológicas empregadas na construção do conhecimento, as interações ciência, tecnologia e sociedade, os desenvolvimentos científicos recentes e suas perspectivas, saber selecionar conteúdos adequados para trabalhar com seus alunos. Enfim é preciso que o professor saiba como continuar sua formação mediante a noção de formas de atualização do conhecimento científico, rompendo com a visão do livro didático como único recurso didático e fonte de toda informação, conforme também afirmam Megid Neto e Fracalanza (2003).

Desta forma, a memória de professores marcantes se destaca por sua personalidade, a sua prática pedagógica, a sabedoria e domínio do conhecimento a ser ensinado, a sua afetividade, e autoridade naturalmente exercida, criatividade e empatia. Porém, também marcam as lembranças nos aspectos negativos, pela ausência de saberes, pelo autoritarismo, pela indiferença e falta de afetividade. Nos trechos a seguir, destacamos relatos de professores que destacaram de forma positiva e também negativa, as experiências com alguns professores que fizeram parte do seu processo estudantil.

“[...] ela era uma professora muito querida, então eu me dedicava muito com ela [...] essa do quarto ano me marcou muito. E tudo isso servia de incentivo para que eu tentasse, para que eu seguisse [...] ela era uma pessoa paciente, ela era uma pessoa que ela tinha carisma pelos alunos. Ela não tinha preguiça de explicar, você não tinha medo de perguntar [...] muito linda - ela usava batom vermelho - eu me lembro muito bem dela." (P7)

“[...] na verdade eu não gostava de matemática porque a professora ela era muito autoritária, e aí eu criei um bloqueio, eu tinha muito medo [...] eи criei um bloqueio com a disciplina, matemática, o que me atrapalhou no decorrer da minha vida toda." (P10)

Destacamos com o relato de P7 a descrição de algumas características da professora de quarto ano que possibilitou deixar marcas: querida, paciente, carisma pelos alunos, não tinha preguiça de explicar. Neste sentido, Tardif (2008) explica acerca de dois aspectos principais sobre o trabalho docente, o primeiro é o conhecimento científico da matéria a ser ensinada e o segundo é o conhecimento prático, ou seja, a prática pedagógica também é um espaço de produção de saberes que lhe são próprios. Desta forma, o professor deixa marcas por meio da interação com o aluno, pois ao organizar pedagogicamente os conteúdos ele traz arraigado consigo a sua filosofia, didática, personalidade, aspectos que fazem parte da individualidade de cada sujeito, já que cada ser é único. Assim, consideramos que as práticas docentes não se formam somente nos cursos de formação, mas que as histórias individuais de cada professor que antecedem o exercício da sua profissão são raízes da construção da sua identidade profissional. Concordando com Nóvoa (1995) que nos diz que é impossível separar o eu profissional do eu pessoal.

Castanho (2001) expõe sobre a importância da postura educadora do professor, pois a cada momento ele pode ver uma oportunidade de interação com o aluno e impulsionar o seu crescimento. O autor o compara a um artista, e destaca algumas características que marcam os alunos: amar o que fazem, valorizar o aluno, explicar bem a matéria, motivar pelas aulas, além 
de serem seres humanos ímpares. "O professor marcante ensina bem, conhece bem a sua área" (Castanho, 2001, p. 157). Com essas palavras, a autora define e explica os diversos relatos de alunos que expressam sobre seus professores, os quais entendiam a matéria, que sabiam explicar, o que significa que o professor domina a estrutura da matéria que ensina e prevê a adequação ao nível do aluno. Neste sentido, Minassi et al (2020) explicam que o desenvolvimento com excelência da carreira docente está ancorado em alguns aspectos como o aperfeiçoamento, um contínuo processo de aprendizagem, a pluralidade metodológica, a dedicação, o gosto e a vontade de exercer a docência, o exemplo e os valores éticos profissionais.

A influência do professor deve ser exercida para promover o aluno. Porém, é comum ouvir relatos de situações que marcaram negativamente a vida estudantil dos indivíduos. Isso fica evidente com o fragmento do relato do entrevistado $\mathrm{P} 9$, o qual ficou com bloqueio na disciplina de matemática atrapalhando-o no decorrer da vida acadêmica. Watanabe \& Gurgel (2016) explicam que memórias como esta geram lembranças de sofrimento escolar, o sentimento de incapacidade intelectual é gerado no aluno quando se vê inapto a resolver problemas em sala de aula, sente vergonha por não saber perante os colegas e professor. Geralmente isto é reforçado por professores autoritários, que não tem paciência com o processo de desenvolvimento da aprendizagem dos alunos.

Por isso, é necessário que o professor compreenda a totalidade de sua profissão, o poder que ela exerce na vida da maioria dos indivíduos que passaram por uma sala de aula, podendo deixar marcas positivas e negativas nas memórias dos alunos ultrapassam contexto escolar.

\section{Considerações Finais}

Com as discussões apresentadas como resultado desta pesquisa foi possível evidenciar a influência que os professores exercem sobre seus alunos em sala de aula. Compreender que uma palavra pode motivar e/ou desmotivar um aluno em seguir seus estudos; aumentar o interesse por uma disciplina ou desenvolver aversão por ela e; influenciar diretamente na escolha da profissão do jovem aluno, contribuindo na decisão do seu futuro profissional.

Também foi possível compreender que um professor marcante não se retém somente as aulas expositivas, mas busca avançar na pluralidade metodológica, considerando os diferentes alunos em sala de aula, abarcando as potencialidades, dificuldades e facilidades de cada um no processo de ensino e aprendizagem.

Destacamos a relevância do domínio do conhecimento científico a ser ensinado, os professores entrevistados foram unânimes em afirmar no decorrer das entrevistas a preocupação em estudar e dominar o assunto a ser desenvolvido em sala de aula, atenuando que esta necessidade formativa é a base para um bom professor. As memórias relatadas de professores que eles admiravam pelo domínio do saber que possuíam foram importantes para a própria formação enquanto professores.

Desta forma, é necessário que o professor compreenda a responsabilidade de sua profissão, que atravessa a história deixando marcas nas lembranças de todos os indivíduos que frequentaram uma sala de aula e que são evocadas nas diversas situações do cotidiano. É nítido, como naturalmente, que ao relatarem acerca da escolha pela profissão, todos os entrevistados foram trazendo memórias de experiências vividas como alunos.

As características para ser um professor que marca positivamente seus alunos não são inatingíveis, a nossa postura e a forma como ensinamos está diretamente ligada a nossa personalidade, aquilo que somos e acreditamos. O professor é aquele que põe o aluno na fronteira da ignorância para o conhecimento, e, conseguir exercer isso com comprometimento, seriedade e qualidade, fará que suas ações atravessem o espaço e o tempo.

Compreendemos também que esta pesquisa não se esgota aqui, ficam como sugestões para próximas pesquisas, os quais nesta investigação não foram possíveis abarcar: a caracterização dos diferentes tipos de personalidades docente; os currículos de formação de professores nas décadas de 1970, 1980, 1990, 2000, 2010 e sua influência na prática docente; 
professores marcantes nas universidades e professores marcantes no rede básica de ensino, diferenças e semelhanças; a importância da prática reflexiva na construção de um professor marcante.

\section{Referências}

Alarcão, I. (2011). Professores reflexivos em uma escola reflexiva. Cortez.

Aranha, M. L. A. (2006). História da Educação e da Pedagogia: geral e Brasil. Moderna.

Borges, M. C., Aquino, O. F. \& Puentes, R. V. (2011). Formação de professores no Brasil: história, políticas e perspectivas. Revista HISTEDBR On-Line, (42), 94-112.

Carvalho, A. M. P. \& Gil-Pérez, D. (2011). Formação de professores de Ciências: tendências e inovações. Cortez.

Castanho, M. E. (2001). Sobre professores marcantes. In: Castanho, S. \& Castanho, M. E. (orgs.) Temas e textos de Metodologia do Ensino Superior. Campinas, SP: Papirus.

Castro, M. G. B. (2006). Uma retrospectiva da formação de professores: histórias e questionamentos. Anais... VI Seminário da Redestrado - Regulação educacional e trabalho docente, UERJ, Rio de Janeiro.

Dias, I. A. (2012). História, Memória e Educação: o que os autores medievais podem nos ensinar? Educação e Fronteiras On-line, 2 (4), $42-61$.

Flick, U. (2009). Introdução à pesquisa qualitativa. Artmed.

Jaerger, W. (1994). Paidéia: A formação do homem grego. Martins Fontes.

Laburú, C. E., Arruda, S. M. \& Nardi, R. (2003). Pluralismo metodológico no ensino de ciências. Ciência \& Educação, 9 (2), 247-260.

Luiz, C. F. (2017). Formação de professores: um estudo sobre a prática reflexiva acerca da avaliação no contexto PIBID/Biologia. Dissertação (Mestrado) Programa de Pós Graduação em Educação, Universidade Estadual do Oeste do Paraná, Campus Cascavel.

Luzuriaga, L. (1983). História da Educação e da Pedagogia. Cia Editora Nacional.

Marrou, H. (2017). História da Educação na antiguidade. Kírion.

Megid Neto, J. \& Fracalanza, H. (2003). O livro didático de ciências: problemas e soluções. Ciência e Educação, 9(2), 147-157. http://www.scielo.br/pdf/ciedu/v9n2/01.pdf.

Minassi, A. S. A., Barlem, A. L. D., Toescher, A. M. R., Mattos, L. M., Gama, B. S. \& Figueira, A. B. (2020). Carreira docente na ótica de alunos de graduação de enfermagem. Revista Research, Society and Development, 9 (5), 1-22. https://rsdjournal.org/index.php/rsd/article/view/3264/2476

Moraes, R. \& Galiazzi, M. C. (2011). Análise textual discursiva. Ed. Unijuí.

Nóvoa, A. (1992). O passado e o presente dos professores. In: Nóvoa, A. (org.). Profissão professor. Porto.

Nóvoa, A. (1995). Formação de professores e profissão docente. In: Nóvoa, A. (Org.). Os professores e a sua formação. Lisboa: Dom Quixote, 15-33.

Paredes, G. G. O. \& Guimarães, O. M. (2012). Compreensões e significados sobre o PIBID para a melhoria da formação de professores de biologia e química. Química Nova na Escola, 34 (4), 266-277.

Penna, F. A. (2014). Negociando a distância entre passado, presente e futuro em sala de aula: a relação entre o tempo histórico e a aprendizagem significativa no ensino de história. Anais... XVI Encontro Regional de História da Anpuh-Rio: Saberes e práticas científicas, Rio de Janeiro.

Pereira, J. E. D. (1999). As licenciaturas e as novas políticas educacionais para a formação docente. Educação \& Sociedade, (68), 109-125.

Quadros, A. L., Carvalho, E., Coelho, F. S., Salviano, L., Gomes, M. F. P. A., Mendonça, P. C. \& Barbosa, R. K. (2005). Os professores que tivemos e a formação da nossa identidade como docentes: um encontro com nossa memória. Revista Ensaio,01 (7), 04-11.

Salla, F. \& Ratier, R. (2010). Por que tão poucos querem ser professor. Revista NOVA ESCOLA, edição especial, fevereiro, 2010.

Silva, M. L. R. (2009). A complexidade inerente aos processos identitários docentes. Notandum Livro 12, CEMOrOC-Feusp, Universidade do Porto.

Tanuri, L. M. (2000). História da formação de professores. Revista Brasileira de Educação, (14), p.61-88.

Tardif, M. (2008). Saberes docentes e formação profissional. Vozes.

Wagner, L. \& Carlesso, J. P. P. (2019). Profissão docente: Um estudo do abandono da carreira na contemporaneidade. Revista Research, Society and Development, 8 (6), 1-13. https://rsdjournal.org/index.php/rsd/article/view/968/851

Watanabe, G. \& Gurgel, I. (2016). As marcas sociais deixadas pelas escolas em nossos professores de Ciências. Contexto e Educação, (99), 116-148. 